\title{
Testosterone Depletion by Castration May Protect Mice from Heat-Induced Multiple Organ Damage and Lethality
}

\author{
Chian-Yuh Lin, ${ }^{1,2}$ Mao-Tsun Lin, ${ }^{3}$ Ruei-Tang Cheng, ${ }^{1,3}$ and Sheng-Hsien Chen ${ }^{4,5}$ \\ ${ }^{1}$ The Institute of Basic Medical Sciences, National Cheng Kung University School of Medicine, Tainan, Taiwan \\ ${ }^{2}$ Department of Pharmacy, Chia-Nan University of Pharmacy and Science, Tainan, Taiwan \\ ${ }^{3}$ Department of Medical Research, Chi Mei Medical Center, Tainan, Taiwan \\ ${ }^{4}$ Department of Obstetrics and Gynecology, Chi Mei Medical Center, Southern Taiwan University, Tainan, Taiwan \\ ${ }^{5}$ Department of Biotechnology, Southern Taiwan University, Tainan, Taiwan
}

Correspondence should be addressed to Sheng-Hsien Chen, cshs159@yahoo.com.tw

Received 1 December 2009; Accepted 3 February 2010

Academic Editor: Rene Anand

Copyright (C 2010 Chian-Yuh Lin et al. This is an open access article distributed under the Creative Commons Attribution License, which permits unrestricted use, distribution, and reproduction in any medium, provided the original work is properly cited.

\begin{abstract}
When the vehicle-treated, sham-operated mice underwent heat stress, the fraction survival and core temperature at $+4 \mathrm{~h}$ of body heating were found to be 5 of 15 and $34.4^{\circ} \mathrm{C} \pm 0.3^{\circ} \mathrm{C}$, respectively. Castration 2 weeks before the start of heat stress decreased the plasma levels of testosterone almost to zero, protected the mice from heat-induced death (fraction survival, 13/15) and reduced the hypothermia (core temperature, $37.3^{\circ} \mathrm{C}$ ). The beneficial effects of castration in ameliorating lethality and hypothermia can be significantly reduced by testosterone replacement. Heat-induced apoptosis, as indicated by terminal deoxynucleotidyl- transferasemediated $\alpha$ UDP-biotin nick end-labeling staining, were significantly prevented by castration. In addition, heat-induced neuronal damage, as indicated by cell shrinkage and pyknosis of nucleus, to the hypothalamus was also castration-prevented. Again, the beneficial effects of castration in reducing neuronal damage to the hypothalamus as well as apoptosis in multiple organs during heatstroke, were significantly reversed by testosterone replacement. The data indicate that testosterone depletion by castration may protect mice from heatstroke-induced multiple organ damage and lethality.
\end{abstract}

\section{Introduction}

Heatstroke is characterized by hyperpyrexia, multiorgan damage and dysfunction, and predominant central nervous system dysfunction (such as delirium, convulsion, or coma) [1-3]. The full spectrum of the signs and symptoms occurring during heatstroke in humans can be mimicked by the rodent heatstroke model [4]. When mice were subjected to acute heat stress, the stress response indicators such as mortality, hypothermia, and multiple organ apoptosis, were observed $[5,6]$. Other line of evidence has accumulated to show that testosterone increases the susceptibility toward a wide variety of infectious diseases including human sepsis [7], shock [8], and severe injury [9]. In addition, depletion of testosterone by castration prior to soft-tissue trauma results in better maintained immune and myocardial function in male mice $[10,11]$. Flutamide, an androgen receptor antagonist, has been shown to restore the depressed cellmediated immunity [12], and cardiac and hepatic function following soft-tissue trauma and hemorrhagic shock [13].
It has also been promoted that testosterone plays a role in the regulation of heat balance in male rats [14]. This raises the possibility that testosterone depletion by castration may protect male mice from heatstroke-induced multiple organ damage and lethality.

To deal with the hypothesis, the effects of surgical castration with or without testosterone replacement on the heatstroke-induced thermoregulatory deficits (in particular, the hypothalamic neuronal damage and apoptosis and hypothermia), multiple organs dysfunction or damage and lethality were assessed in mice $[5,6]$.

\section{Materials and Methods}

2.1. Mice. All the experiments were carried out in accordance with the ethical guidelines laid down by the committee for the purpose of control and supervision of experiments on animals, Chi Mei Medical Center (Tainan, Taiwan). ICR inbred male mice, 8 weeks old, were given food and water 
ad libitum and acclimatized to room temperature at $24^{\circ} \mathrm{C}$, relative humidity $(\mathrm{RH})$ of $50 \pm 8 \%$, and a $12 \mathrm{~h}$ dark/light cycle for 1 week before the start of the experiment at least.

2.2. Murine Model of Heatstroke. Animals were exposed to heat stress treatment $\left(41.2^{\circ} \mathrm{C}, \mathrm{RH}-50-55 \%, 1 \mathrm{~h}\right)$ in an environment-controlled chamber [5]. The time at which mice were removed from the environmental chamber was called 0 hour. The heat-stressed mice were returned to the normal room temperature $\left(25^{\circ} \mathrm{C}\right)$ after the end of the heat exposure. Mice that survived on day 4 of heat treatment were considered survivors, and the data were used for analysis of the results. Core temperatures were measured every 5 minutes with a copper constantan thermocouple inserted into the rectum and connected to a thermometer (HR1300, Yokogawa, Tokyo, Japan). After the $1 \mathrm{~h}$ heating period, animals were properly fed and hydrated. Heatstroke resembles sepsis in many aspects $[15,16]$. Like many sepsis studies, we use death as an endpoint in conscious mice in this study

2.3. Castration Procedures. Fourteen days before the experiment, mice were castrated or sham-operated. Briefly, after the initiation of general anesthesia with ketamine and Xylazine ( 8.7 and $1.3 \mathrm{mg} / 100 \mathrm{~g} \mathrm{BW}, \mathrm{IM}$ ) and application of $75 \%$ alcohol to disinfect the scrotum, a small midline incision was made and the testes were exteriorized. The spermatic vessels were tied with 4.0 silk sutures, and the testes were removed. The incision was then closed with 4.0 silk sutures. In sham-operated mice, the skin of the scrotum was incised to draw out and back the testes and closed with sutures only. An interval of 14 days after castration was chosen for subcutaneously implanting testosterone or heat stress experiments because previous studies have demonstrated the absence of any detectable plasma testosterone levels at this interval [11].

2.4. Testosterone Supplement. For testosterone replacement study, the castrated groups were subcutaneously implanted with testosterone 2 weeks after the castration. Briefly, after the initiation of general anesthesia with ketamine and Xylazine ( 8.7 and $1.3 \mathrm{mg} / 100 \mathrm{~g} \mathrm{BW}$, IM), a small incision was made in the skin of the back, a pellet of testosterone $(0.5 \mathrm{mg} / \mathrm{pellet}, 21$-day release; Innovative Research) was subcutaneously implanted. For the other sham-implanted animals, the skin of the back was incised and then closed with 3.0 silk suture only. Animals were subjected to thermal experiments 2 weeks after implanted surgery.

2.5. Experimental Groups. Four major groups of animals were designated for the experiment. In the normothermic control (NC) groups, the animals were exposed to room temperature $\left(26^{\circ} \mathrm{C}\right)$ throughout the entire experiments. The sham-operated heatstroke $(\mathrm{SOH})$ mice, the castrated, vehicle-treated heatstroke $(\mathrm{CVH})$ mice, and the castrated, testosterone-treated heatstroke $(\mathrm{CTH})$ mice were treated with heat regimen of $41.2^{\circ} \mathrm{C}$ for $1 \mathrm{~h}$. Before the start of experiments, their core temperature was within the normal body temperature range of $37.0 \sim 37.6$.

2.6. Blood Sampling and Plasma Testosterone Assays. Peripheral blood samples were harvested from urethaneanesthetized mice $(1.4 \mathrm{~g} / \mathrm{kg} \mathrm{BW}, \mathrm{IP})$ by heart puncture via a syringe containing $3.8 \%$ sodium citrate $(9: 1 \mathrm{vol} / \mathrm{vol})$. The blood was centrifuged to isolate upper layer plasma. Plasma concentration of testosterone was measured by enzyme immunoassay (EIA) as described in the instructions provided by manufacturer's kits (Cayman Chemical USA, Catalog No.582701), which presents $6 \mathrm{pg} / \mathrm{mL}$ of sensitivity, and $100 \%$ of specificity.

\subsection{Terminal Deoxynucleotidyl Transferase-Mediated dUTP} Nick-End Labeling (TUNEL) Assays. The heat-treated mice were sacrificed at "heat off $2.5 \mathrm{~h}$ " under the heat stress model. Perfusion and prefixed procedure with the PBS and $10 \%$ formaldehyde were performed after the general anesthesia with urethane $(1.4 \mathrm{~g} / \mathrm{kg} \mathrm{BW}, \mathrm{IP})$. The brain, liver, spleen, and kidney were excised and postfixed in a solution containing $30 \%$ sucrose and $10 \%$ formaldehyde for at least 24 hours. After fixation, the organs were embedded separately in Tissue Tek OCT embedding medium (Miles). Snap frozen samples were cryostat sectioned ( $8 \mu \mathrm{m}$ thick) and placed on slides coated with poly-L-lysine for TUNEL assays. TUNEL staining was done using a BD ApoAlert DNA Fragmentation Assay kit (BD Biosciences-Clontech), according to detailed protocol provided by manufacture. In brief, tissue slides were pretreated with $20 \mu \mathrm{g} / \mathrm{mL}$ proteinase $\mathrm{K}$ solution for 5 minutes and were incubated with the reaction mixture containing terminal deoxynucleotidyl transferase (TdT) and fluorescein-conjugated deoxyuridine triphosphate (dUTP) for 1 hour at $37^{\circ} \mathrm{C}$. Afterwards, sections were washed with PBS, their nuclei were costained with 4,6diamidino-2-phenylindole (DAPI) using DAPI-containing VectashieldR Mounting Medium (VECTOR Laboratories, Burlingame, CA), and subsequently analyzed using Olympus E800 fluorescent microscope equipped with Olympus Coolpix 995 digital camera (both from Olympus, Japan). Apoptosis induction efficacy was calculated as percentage of fluorescein-positive to DAPI-stained nuclei.

2.8. Neuronal Damage Score. At the end of experiment, the brain was removed, fixed in $10 \%$ neutral buffered formalin, and embedded in paraffin blocks. Serial $(5 \mu \mathrm{m})$ sections through the hypothalamus were stained with hematoxylin and eosin for microscopic evaluation. The extent of hypothalamic neuronal damage was scored on a scale of $0-3$, modified from the grading system of Pulsinelli et al. [17], in which 0 is normal 1 indicates that approximately $30 \%$ of the neurons were damaged, 2 indicates that approximately $60 \%$ of the neurons were damaged, and 3 indicates that approximately $100 \%$ of the neurons are damaged. Each hemisphere was evaluated independently without the examiner knowing the experimental conditions. Degenerative damage was considered to have occurred in any neurons showing pyknosis of the nucleus and cell shrinkage. 


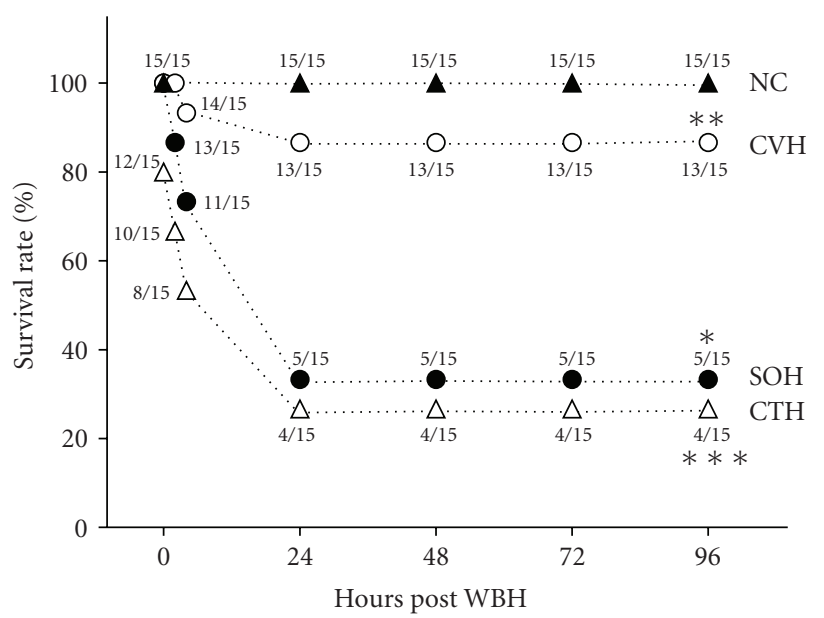

FIgure 1: Percentage of survival for normothermic controls (NCs), castrated, vehicle-treated heatstroke $(\mathrm{CVH})$ mice, sham-operated, vehicle-treated heatstroke $(\mathrm{SOH})$ mice, and castrated, testosteronetreated heatstroke $(\mathrm{CTH})$ mice. ${ }^{*} P<.05$ compared with $\mathrm{NC}$ group. ${ }^{* *} P<.05$ compared with $\mathrm{SOH}$ group. ${ }^{* * *} P<.05$ compared with $\mathrm{CVH}$ group.

2.9. Statistical Analysis. All values, except those on Table 3, are expressed as the mean \pm SEM and were analyzed by one-way analysis of variance followed by the Fisher's least significance test as a post hoc test for multiple comparisons among means. For the data in Table 3, the Wilcoxon signedrank test was used. The Wilcoxon tests convert the scores or values of a variable to ranks, require calculation of the sum of the ranks, and provide critical values for the sum necessary to test the null hypothesis at a given level of significance. These data are presented as the "median," followed by first and third quartiles. All results were considered statistically significant at $P<.05$.

\section{Results}

3.1. Castration Attenuates Heat-Induced Lethality and Thermoregulatory Deficit. WBH treatment was used to induce heatstroke and thermoregulatory deficit (e.g., hypothermia) in mice as described in Section 2. Both Figures 1 and 2 indicate that $1 \mathrm{~h}$ of $\mathrm{WBH}$ resulted in 33\% mortality and hypothermia $\left(\sim 27^{\circ} \mathrm{C}\right.$ core temperature) monitored at $4 \mathrm{~h}$ of $\mathrm{WBH}$ in $\mathrm{SOH}$ mice. However, in $\mathrm{CVH}$ mice, the values of both percentage of survival and core temperature were significantly reached to new levels of $87 \%$ and $34.5^{\circ} \mathrm{C}$, respectively. When the $\mathrm{CTH}$ groups were exposed to the same heat treatment, the values of both percentage of survival and core temperature were significantly returned to $27 \%$ and $28^{\circ} \mathrm{C}$, respectively.

3.2. Castration Decreases Plasma Levels of Testosterone. Table 1 summarizes the plasma levels of testosterone for different groups of mice monitored at $4 \mathrm{~h}$ of $\mathrm{WBH}$ in $\mathrm{SOH}, \mathrm{CVH}$, and $\mathrm{CTH}$ groups or the equivalent time in $\mathrm{NC}$ group. As compared to those of $\mathrm{NC}$ or $\mathrm{SOH}$ groups,

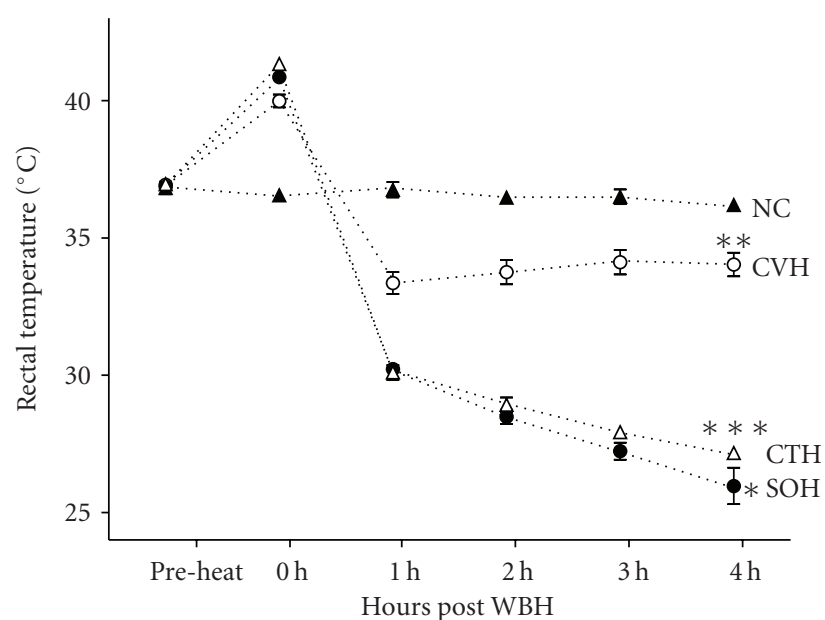

FIgURE 2: The rectal temperature changes 1-4 hours post-whole body heating (WBH) for normothermic controls (NC), castrated, vehicle-treated heatstroke $(\mathrm{CVH})$ mice, castrated, testosteronetreated heatstroke $(\mathrm{CTH})$ mice, and sham-operated, heatstroke $(\mathrm{SOH})$ mice. Data are means \pm SEM $(n=6 \sim 9) .{ }^{*} P<.05$ compared with NC group. ${ }^{* *} P<.05$ compared with $\mathrm{SOH}$ group. ${ }^{* * *} P<.05$ compared with $\mathrm{CVH}$ group.

TABLe 1: Plasma levels of testosterone for different groups of mice.

\begin{tabular}{lc}
\hline Treatment groups & $\begin{array}{c}\text { Plasma testosterone } \\
(\mathrm{pg} / \mathrm{mL})\end{array}$ \\
\hline (1) Normothermic controls (NCs) & $403 \pm 91$ \\
(2) Sham-operated heatstroke (SOH) mice & $525 \pm 115$ \\
$\begin{array}{l}\text { (3) Castrated, vehicle-treated heatstroke } \\
\text { (CVH) mice }\end{array}$ & $4 \pm 2^{*}$ \\
(4) Castrated, testosterone-treated & $260 \pm 24^{*, * *}$ \\
heatstroke (CTH) mice &
\end{tabular}

${ }^{*} P<.01$ in comparison with group 1 or group 2 ;

$* * P<.05$ in comparison with group 3 . The blood sampling was obtained for testosterone assay immediately before the start of thermal experiments (or 14 days after vehicle or testosterone treatment). Data are means \pm SEM of 7 mice per group.

the CVH mice displayed significantly lower levels of plasma testosterone $(4 \pm 2 \mathrm{pg} / \mathrm{mL}$ versus $403 \pm 91$ or $525 \pm 115 \mathrm{pg} / \mathrm{mL})$. However, CTH mice showed significantly higher levels of plasma testosterone $(260 \pm 24 \mathrm{pg} / \mathrm{mL}$ versus $4 \pm 2 \mathrm{pg} / \mathrm{mL})$ as compared to those of CVH (Table 1).

3.3. Castration Attenuates Heat-Induced Increased Numbers of TUNEL-Positive Cells in Hypothalamus. As summarized in Table 2, the numbers of TUNEL-positive cells in the hypothalamus evaluated at $2.5 \mathrm{~h}$ postWBH were $0,344 \pm$ $107,70 \pm 17$, and $312 \pm 95$ per hypothalamic section, respectively, for $\mathrm{NC}(n=7)$, SOH mice $(n=7)$, CVH $(n=7)$, and CTH $(n=7)$. Photomicrographs of TUNEL-positive cells in the hypothalamus of an NC, a SOH mouse, a CVH mouse, and a CTH mouse were shown in Figures 3(a) to 3(d). As compared to those of NC group, $\mathrm{SOH}$ mice had higher numbers of TUNEL-positive cells in their hypothalami (Figure 3(b)). The heat-induced increased 
TABLE 2: Mean ( \pm SEM) number of TUNEL-positive cells per tissue section for different groups of mice.

\begin{tabular}{lc}
\hline Treatment groups & $\begin{array}{c}\text { Hypothalamus } \\
\text { spleen kidney }\end{array}$ \\
\hline $\begin{array}{l}\text { (1) Normothermic controls (NCs) } \\
\text { (2) Sham-operated, vehicle-treated }\end{array}$ & 0 \\
heatstroke (SOH) mice & $344 \pm 107^{*}$ \\
(3) Castrated, vehicle-treated heatstroke & $70 \pm 17^{* *}$ \\
(CVH) mice & \\
(4) Castrated, testosterone-treated & $312 \pm 95^{* * *}$ \\
\hline
\end{tabular}

${ }^{*} P<.05$ in comparison to group 1 ; ${ }^{* *} P<.05$ in comparison to group 2 ;

${ }^{* * *} P<.05$ in comparison to group 3. Vehicle or testosterone was administered 14 days before whole body heating, and the tissue section was obtained for TUNEL assay $2.5 \mathrm{~h}$ post-WBH. Data are means \pm SEM of 7 mice per group

numbers of hypothalamic TUNEL-positive cells could be significantly reduced by castration (Figure 3(c)). However, the beneficial effects of castration were significantly reversed by testosterone replacement (Figure 3(d)).

\subsection{Castration Reduces Heat-Induced Neuronal Damage Cell} Shrinkage and Nucleus Pyknosis in Hypothalamus. Table 3 summarizes the effects of heat exposure on the neuronal damage scores of the hypothalamus from $\mathrm{NC}$ mice, $\mathrm{SOH}$ mice, $\mathrm{CVH}$ mice, or CTH mice. The scores for hypothalamic neuronal damage in $\mathrm{SOH}$ mice significantly $(P<.05)$ exceeded those of the respective $\mathrm{NC}$ mice. However, the hypothalamic neuronal damage scores in $\mathrm{CVH}$ mice were significantly $(P<.05)$ lower than those of $\mathrm{SOH}$ mice. Furthermore, it was found that the hypothalamic neuronal damage score in CTH mice were significantly $(P<.05)$ higher than those of $\mathrm{CVH}$ mice. Two and half hours after termination of heat stress, $\mathrm{SOH}$ mice exhibited cell shrinkage and pyknosis of the nucleus in the hypothalamus (Figure 4(b)). The heatstroke-induced neuronal damage in the hypothalamus was markedly less in $\mathrm{CVH}$ mice (Figure $4(\mathrm{c})$ ) or CTH mice (Figure $4(\mathrm{~d})$ ). Both TUNEL and $\mathrm{HE}$ stainings revealed that apoptosis, cell shrinkage and pyknosis that occurred in the hypothalamus of a $\mathrm{SOH}$ (Figure 5(b)) mouse could be reduced by castration as shown in a CVH mouse (Figure 5(c)), which could be reversed by testosterone replacement in a CTH mouse (Figure 5(d)).

\subsection{Castration Downregulates the Heat Stress-Induced Apop-} tosis in Splenocytes, Hepatocytes, and Kidney Cells. TUNEL assays of splenocytes, hepatocytes, and kidney cells were done $2.5 \mathrm{~h}$ after the termination of heat stress for different groups of mice. The numbers of TUNEL-positive cells of spleen, and kidney from SVH mice were significantly higher than those of NC mice (Table 2). As compared to SOH mice, $\mathrm{CVH}$ mice had significantly lower numbers of TUNEL-positive cells in multiple organs (Table 2). In addition, the CTH mice showed significantly higher numbers of TUNEL-positive in all these 3 organs as compared to those of CVH mice. Photomicrographs showing examples of TUNEL-positive
TABle 3: Mean $( \pm$ SEM) of neuronal damage score values in hypothalamus for different groups of mice.

\begin{tabular}{lc}
\hline Treatment groups & $\begin{array}{c}\text { Neuronal } \\
\text { damage score }\end{array}$ \\
\hline $\begin{array}{l}\text { (1) Normothermic controls (NCs) } \\
\text { (2) Sham-operated, vehicle-treated } \\
\text { heatstroke (SOH) mice }\end{array}$ & $0(0,0)$ \\
$\begin{array}{l}\text { (3) Castrated, vehicle-treated heatstroke } \\
\text { (CVH) mice }\end{array}$ & $2(2,2)^{*}$ \\
(4) Castrated, testosterone-treated & $0(0,0.25)^{* *}$ \\
heatstroke (CTH) mice & $1(1,1)^{* * *}$ \\
\hline
\end{tabular}

${ }^{*} P<.05$ in comparison to group $1 ;{ }^{* *} P<.05$ in comparison to group 2 ; $* * * P<.05$ in comparison to group 3 . Vehicle or testosterone was administered 14 days before whole body heating (WBH), and the tissue section was obtained for neuronal damage score assay $2.5 \mathrm{~h}$ post-WBH. Data are means \pm SEM of 7 mice per group

cells of spleen and kidney for different groups of mice were depicted in both Figures 6 and 7, respectively.

\section{Discussion}

It has been demonstrated that plasma levels of estradiol are related to heat tolerance in anesthetized rats [18]. For example, the heat tolerance of estrus female rats was superior to the heat tolerance of ovariectomized or leuprolide-treated female rats. Induction of high levels of plasma estradiol caused by intravenous delivery of a high dose $(1 \mathrm{~mL} / \mathrm{kg})$ of Premarin in estrus female, ovariectomized, or leuprolidetreated female rats conferred protection after heatstroke occurrence, as reflected by prolonged survival time. Evidence has also been provided to suggest that Premarin can act via estrogen receptors to rescue the unanesthetized, unrestrained mice from heatstroke-induced lethality [6]. In the present study, we have further evidence to promote that testosterone depletion by castration is able to protect the unanesthetized, unrestrained mice from heatstroke-induced lethality. It appears that low testosterone and/or high estradiol are able to protect mice from heatstroke-induced lethality. The contention is consistent with several clinical and experimental studies which demonstrate that gender dimorphism in immune and organ responsiveness and in the susceptibility and morbidity from shock, trauma, and sepsis [19]. In view of these findings, clinically relevant therapeutic strategies should be performed using estrogen or Premarin, and/or the androgen receptor antagonist, flutamide in heatstroke victims since heatstroke resembles sepsis in many aspects $[15,16]$.

Testosterone produced by Leydig cells of the testes is the major androgen in the circulation of men and adult males of most mammalian species. Androgen may proceed to amplify the action of testosterone through its conversion to dihydroxatone or its aromatization to estradiol [20]. This raises the possibility that the increased levels of both dihydrosterone and estradiol may be induced following castration-induced testosterone depletion in the current model. However, our findings reveal that castration does not 


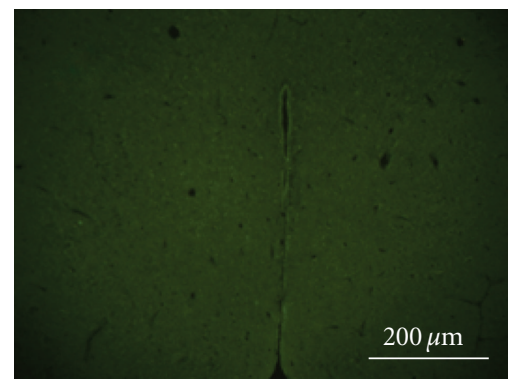

(a)

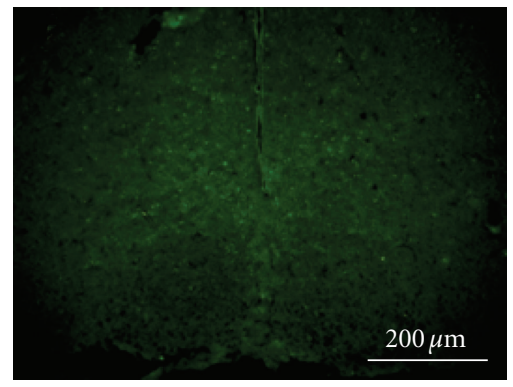

(c)

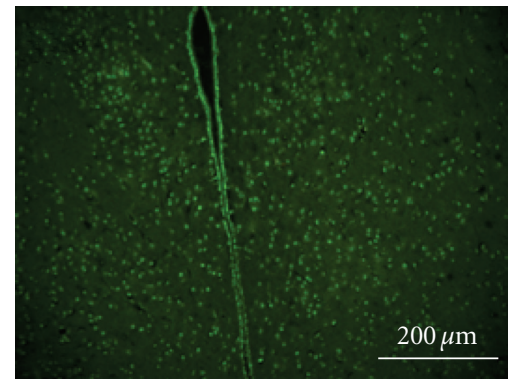

(b)

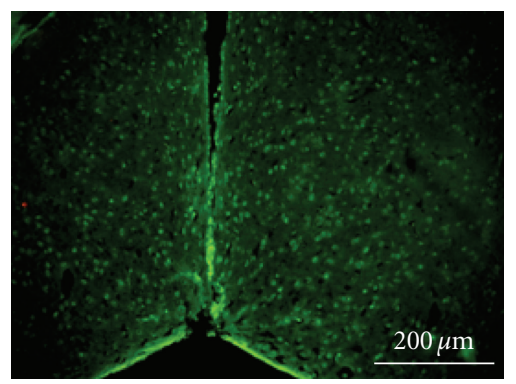

(d)

FIGURE 3: Photomicrographs of TUNEL, staining of the hypothalamus for a normothermic control (NC) (a), a sham-operated, heatstroke $(\mathrm{SOH})$ mouse $(\mathrm{b})$, a castrated, vehicle-treated heatstroke $(\mathrm{CVH})$ mouse $(\mathrm{c})$, and a castrated, testosterone-treated $(\mathrm{CTH}) \mathrm{mouse}(\mathrm{d})$.

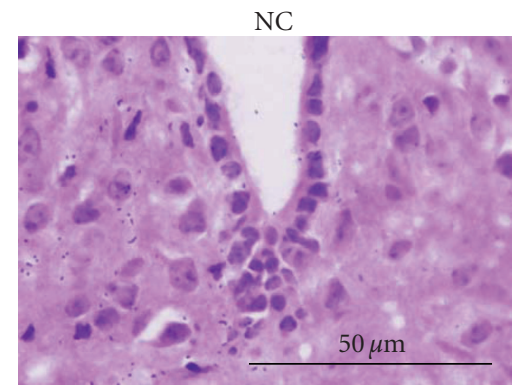

(a)

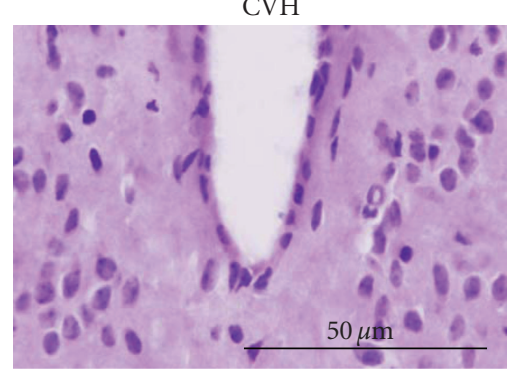

(c)

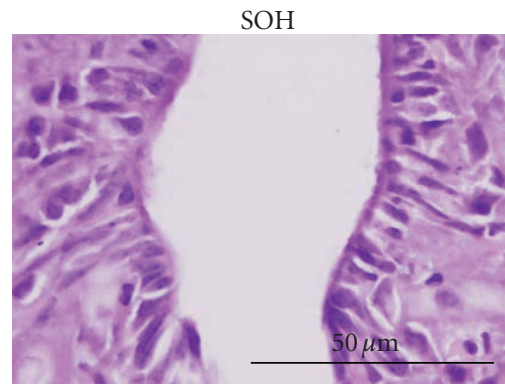

(b)

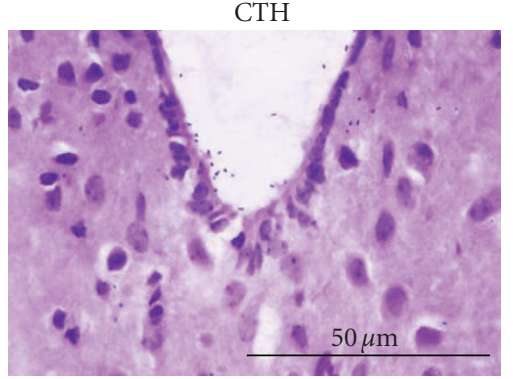

(d)

FIGURE 4: Photomicrographs of neuronal damage of the hypothalamus of a normothermic control (NC) (a), a sham-operated vehicle-treated heatstroke $(\mathrm{SOH})$ mouse (b), a castrated, vehicle-treated heatstroke $(\mathrm{CVH})$ mouse (c), and a castrated, testosterone-treated heatstroke $(\mathrm{CTH})$ mouse (d). Two and half hours post-whole body heating, the hypothalamus of a SOH mouse or a CTH mouse showed cell shrinkage, pyknosis of the nucleus, and loss of Nissl substance. However, following castration, neuroprotection was induced (as shown in a CVH mouse) $\times 200$. 

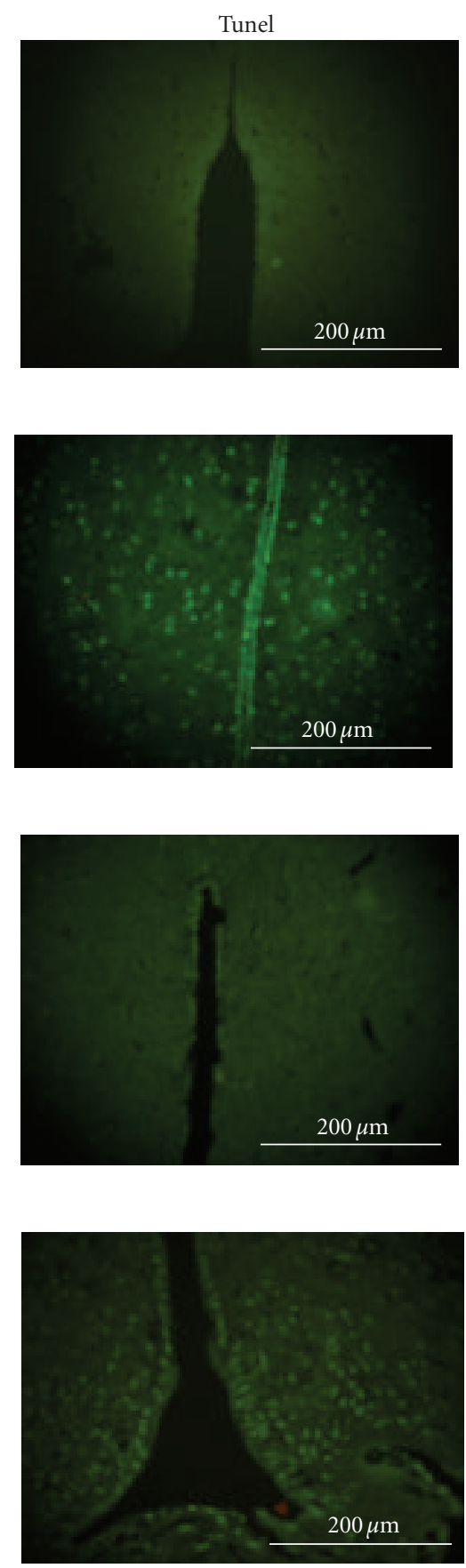

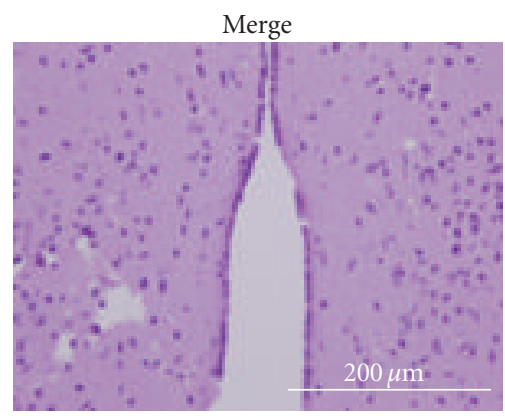

(a)
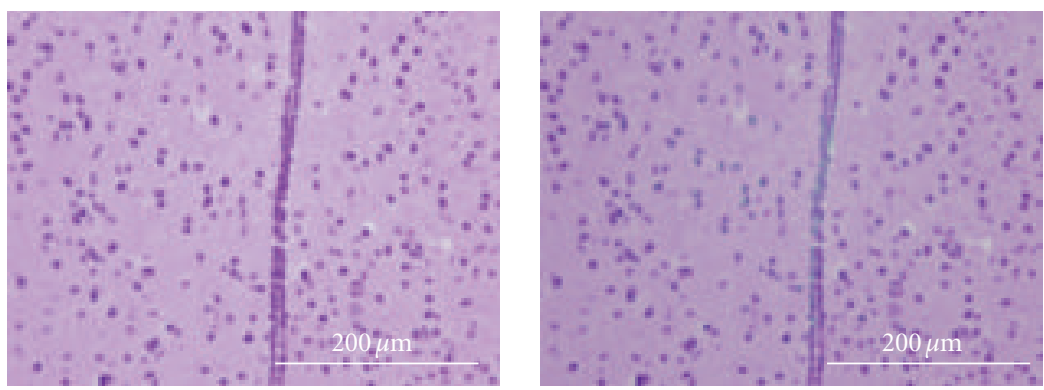

(b)
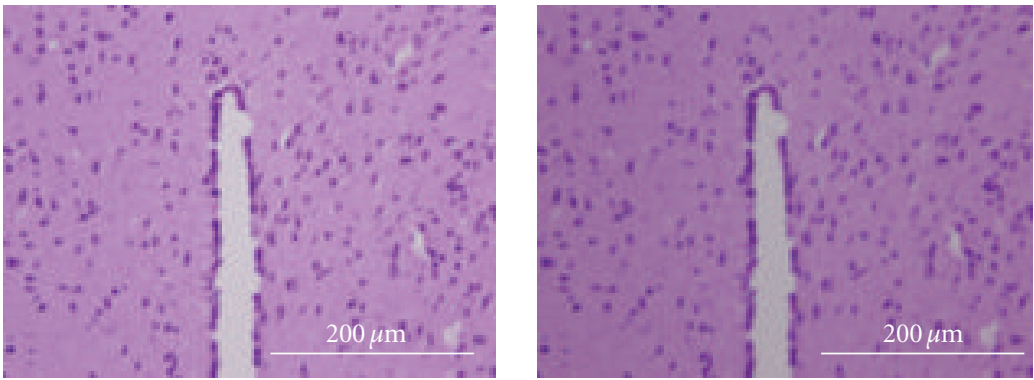

(c)
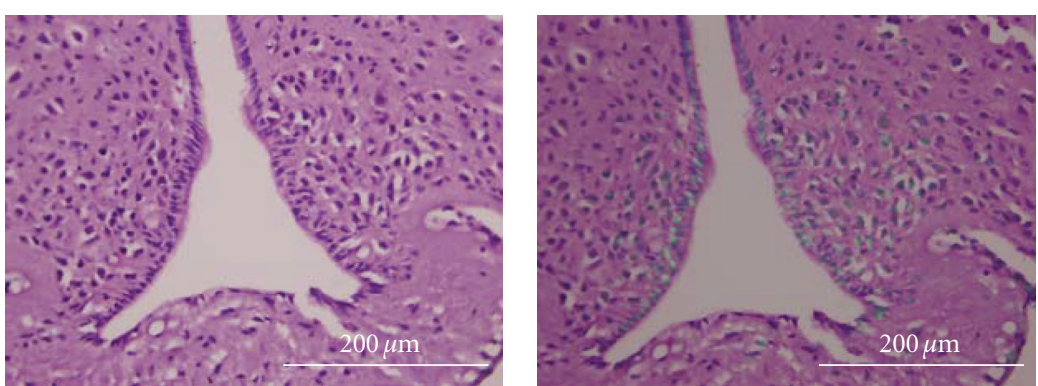

(d)

Figure 5: Photomicrographs of TUNEL, HE, and merged (TUNEL+HE) staining of the hypothalamus of an NC mouse (a), a SOH mouse (b), a CVH mouse (c), and a CTH mouse (d). Apoptosis (green fluorescence; TUNEL staining) broadly colocalized with HE staining (purple color) of neurons to yield the blue color. Apoptosis is associated with pyknosis of the nucleus (b and $d) \times 400$.

affect the plasma levels of both dihydrosterone and estradiol in our mice and indicate that low testosterone, rather than high estradiol, is the main cause for the beneficial effect of castration in preventing heat-induced lethality (the data are not shown here).

Our previous results have shown that mice display increased production of cellular ischemia (e.g., glutamate and lactate-to-pyruvate ratio) and injury (e.g., glycerol) markers in the hypothalamus following heatstroke [6]. The current findings further show that both apoptosis (as indicated by TUNEL staining) and neuronal damage (as indicated by both cell shrinkage and pyknosis by $\mathrm{H}$ and E staining) in the hypothalamus occur during heatstroke. Apparently, the hypothermia that occurred after heatstroke 


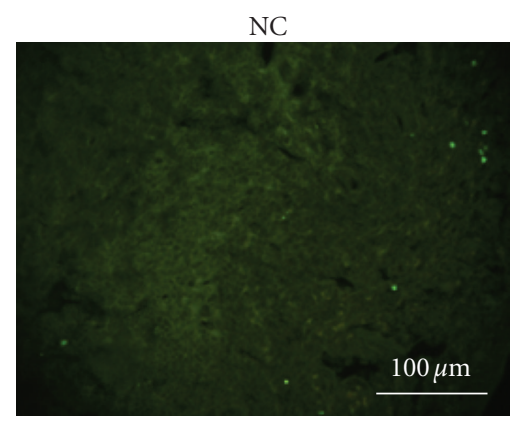

(a)

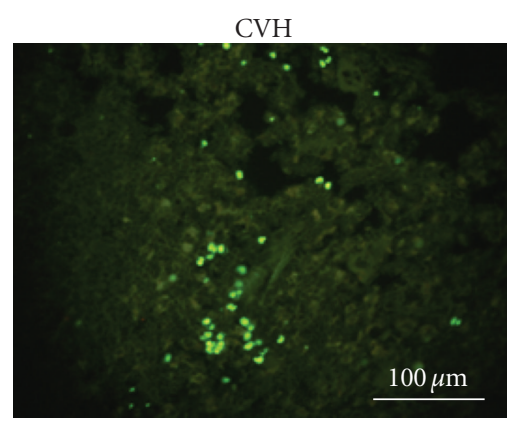

(c)

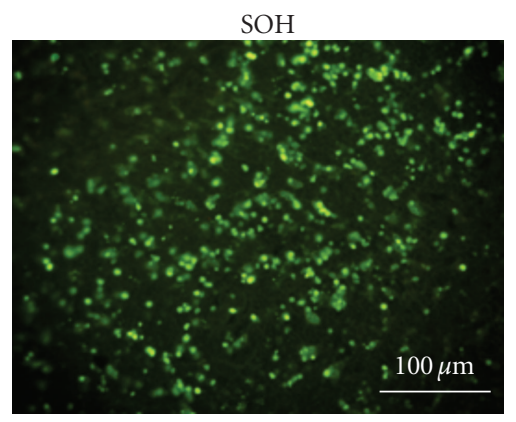

(b)

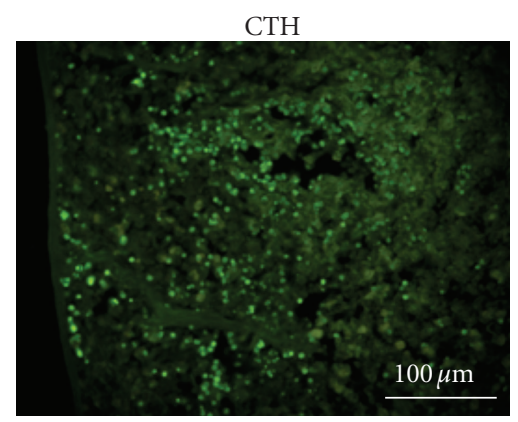

(d)

FIgURE 6: Photomicrographs of TUNEL staining of the spleen for an NC mouse, a SOH mouse, a CVH mouse, and a CTH mouse.

NC

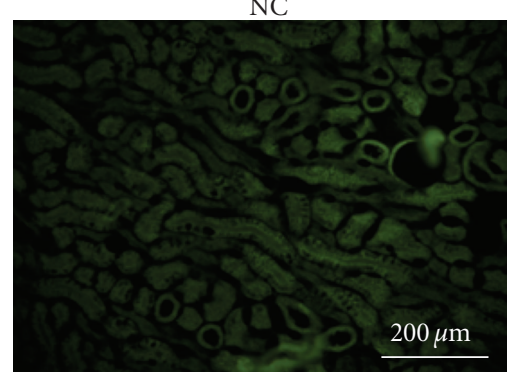

(a)

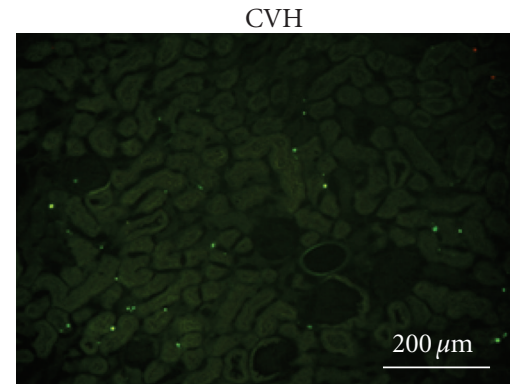

(c)

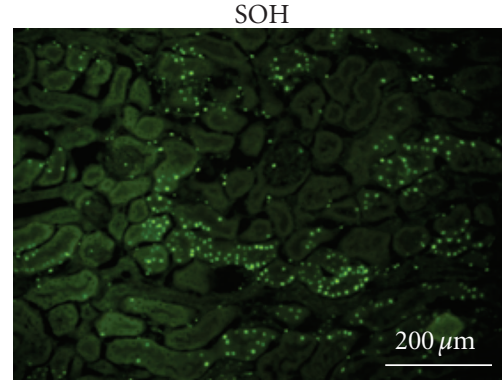

(b)

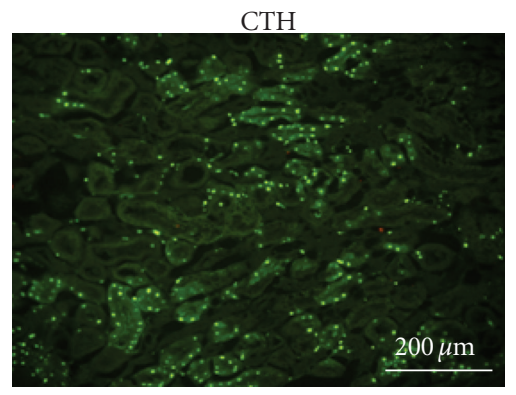

(d)

FIGURE 7: Photomicrographs of TUNEL staining of the kidney for an NC mouse, a SOH mouse, a CVH mouse, and a CTH mouse.

in mice $[5,6]$ may have resulted from neuronal apoptosis and degeneration in the hypothalamus. The heat-induced thermoregulatory deficits as well as neuronal degeneration and apoptosis in the hypothalamus can be significantly prevented by testosterone depletion caused by surgical castration (as shown in the present results). Furthermore, the beneficial effects of testosterone in preventing neuronal damage and apoptosis in the hypothalamus and thermoregulatory deficit (e.g., hypothermia occurs during room temperature exposure) can be reversed after testosterone replacement. 
In addition to ischemic damage to the hypothalamus, severe heat causes apoptosis of spleen and renal cells, which can be ameliorated by testosterone depletion.

As mentioned in the Introduction section, multiorgan dysfunctions ensued from severe heatstroke include cardiac depression, cerebral ischemia and neuronal damage, systemic inflammation, hepatic and renal failure, systemic inflammation, and hypercoagulable state. The increased proinflammatory cytokine release by kupffer cells normally observed in intact inflammatory male mice following trauma-hemorrhage can be prevented by castration [12, $21,22]$. Castration of male rats 2 weeks prior to the onset of trauma-hemorrhage prevented the depression of myocardial function [10]. Flutamide (an androgen receptor antagonist) has also been shown to prevent the depression of cardiovascular responses following trauma and severe blood loss in male rats [14]. In addition, evidence has accumulated to indicate that testosterone is able to enhance both platelet aggregation [23, 24] and vasoconstriction $[25,26]$. These observations prompted us to think that testosterone depletion may improve heat tolerance during heatstroke by reducing multiple organ dysfunction.

In summary, the current results demonstrate that testosterone depletion by castration may rescue mice from heatinduced multiple organ damage and lethality. In order to transfer those effects into clinical usage, studies mimicking castration by the use of an androgen receptor antagonist such as Flutamide should be conducted following the onset of heatstroke in future studies.

\section{Acknowledgment}

This study was supported by grants from the National Science Council, Taipei, Taiwan and the Chi Mei Medical Center (Tainan, Taiwan).

\section{References}

[1] A. Bouchama and J. P. Knochel, "Heat stroke," The New England Journal of Medicine, vol. 346, no. 25, pp. 1978-1988, 2002.

[2] J. P. Knochel and G. Reed, "Disorders of heat regulation," in Clinical Disorders of Fluid and Electrolyte Mechanism, M. H. Maxwell, C. R. Kleeman, and R. G. Narins, Eds., pp. 15491590, McGraw-Hill, New York, NY, USA, 5th edition, 1994.

[3] T. F. O'Donnell Jr. and G. H. Clowes Jr., "The circulatory abnormalities of heat stroke," The New England Journal of Medicine, vol. 287, no. 15, pp. 734-737, 1972.

[4] C.-K. Chang, C.-P. Chang, W.-T. Chiu, and M.-T. Lin, "Prevention and repair of circulatory shock and cerebral ischemia/injury by various agents in experimental heatstroke," Current Medicinal Chemistry, vol. 13, no. 26, pp. 3145-3154, 2006.

[5] S. Chatterjee, S. Premachandran, D. Sharma, R.S. Bagewadikar, and T. B. Poduval, "Therapeutic treatment with $\mathrm{L}$-arginine rescues mice from heat stroke-induced death: physiological and molecular mechanisms," Shock, vol. 24, no. 4, pp. 341-347, 2005.

[6] K.-H. Shen, C.-H. Lin, H.-K. Chang, W.-C. Chen, and S.-H. Chen, "Premarin can act via estrogen receptors to rescue mice from heatstroke-induced lethality," Shock, vol. 30, no. 6, pp. 668-674, 2008.

[7] J. Schröder, V. Kahlke, K.-H. Staubach, P. Zabel, and F. Stüber, "Gender differences in human sepsis," Archives of Surgery, vol. 133, no. 11, pp. 1200-1205, 1998.

[8] M. K. Angele, M. G. Schwacha, A. Ayala, and I. H. Chaudry, "Effect of gender and sex hormones on immune responses following shock," Shock, vol. 14, no. 2, pp. 81-90, 2000.

[9] A. Oberholzer, M. Keel, R. Zellweger, U. Steckholzer, O. Trentz, and W. Ertel, "Incidence of septic complications and multiple organ failure in severely injured patients is sex specific," The Journal of Trauma, vol. 48, no. 5, pp. 932-937, 2000.

[10] D. E. Remmers, W. G. Cioffi, K. I. Bland, P. Wang, M. K. Angele, and I. H. Chaudry, "Testosterone: the crucial hormone responsible for depressing myocardial function in males after trauma-hemorrhage," Annals of Surgery, vol. 227, no. 6, pp. 790-799, 1998.

[11] M. W. Wichmann, R. Zellweger, C. M. DeMaso, A. Ayala, and I. H. Chaudry, "Mechanism of immunosuppression in males following trauma-hemorrhage: critical role of testosterone," Archives of Surgery, vol. 131, no. 11, pp. 1186-1192, 1996.

[12] M. W. Wichmann, M. K. Angele, A. Ayala, W. G. Cioffi, and I. H. Chaudry, "Flutamide: a novel agent for restoring the depressed cell-mediated immunity following soft-tissue trauma and hemorrhagic shock," Shock, vol. 8, no. 4, pp. 242248, 1997.

[13] D. E. Remmers, P. Wang, W. G. Cioffi, K. I. Bland, and I. H. Chaudry, "Testosterone receptor blockade after traumahemorrhage improves cardiac and hepatic functions in males," American Journal of Physiology, vol. 273, no. 6, pp. H2919H2925, 1997.

[14] N. Shvareva, J. Kaplanski, L. Abramovich, and U. A. SodMoriah, "Testosterone modifies response to chronic heat exposure in rats," Comparative Biochemistry and Physiology Part A, vol. 120, no. 4, pp. 575-578, 1998.

[15] H. Grogan and P. M. Hopkins, "Heat stroke: implications for critical care and anaesthesia," British Journal of Anaesthesia, vol. 88, no. 5, pp. 700-707, 2002.

[16] K.-C. Lu, J.-Y. Wang, S.-H. Lin, P. Chu, and Y.-F. Lin, "Role of circulating cytokines and chemokines in exertional heatstroke," Critical Care Medicine, vol. 32, no. 2, pp. 399-403, 2004.

[17] W. A. Pulsinelli, J. B. Brierley, and F. Plum, "Temporal profile of neuronal damage in a model of transient forebrain ischemia," Annals of Neurology, vol. 11, no. 5, pp. 491-498, 1982.

[18] S.-H. Chen, F.-M. Chang, K.-C. Niu, M. Y.-S. Lin, and M.-T. Lin, "Resuscitation from experimental heatstroke by estrogen therapy," Critical Care Medicine, vol. 34, no. 4, pp. 1113-1118, 2006.

[19] M. K. Angele, M. C. Frantz, and I. H. Chaudry, "Gender and sex hormones influence the response to trauma and sepsispotential therapeutic approaches," Clinics, vol. 61, no. 5, pp. 479-488, 2006.

[20] B. Bilińska, B. Wiszniewska, K. Kosiniak-Kamysz, et al., "Hormonal status of male reproductive system: androgens and estrogens in the testis and epididymis. In vivo and in vitro approaches," Reproductive Biology, vol. 6, supplement 1, pp. 43-58, 2006.

[21] M. K. Angele, M. W. Knöferl, M. G. Schwacha, et al., "Sex steroids regulate pro- and anti-inflammatory cytokine release by macrophages after trauma-hemorrhage," American Journal of Physiology, vol. 277, no. 1, pp. C35-C42, 1999. 
[22] A. Ayala, M. M. Perrin, W. Ertel, and I. H. Chaudry, "Differential effects of hemorrhage on Kupffer cells: decreased antigen presentation despite increased inflammatory cytokine (IL-1, IL-6 and TNF) release," Cytokine, vol. 4, no. 1, pp. 6675, 1992.

[23] M. Johnson, E. Ramey, and P. W. Ramwell, "Androgen mediated sensitivity in platelet aggregation," American Journal of Physiology, vol. 232, no. 4, pp. H381-385, 1977.

[24] A. Uzunova, E. Ramey, and P. W. Ramwell, "Effect of testosterone, sex and age on experimentally induced arterial thrombosis," Nature, vol. 261, no. 5562, pp. 712-713, 1976.

[25] A. A. L. Ajayi, R. Mathur, and P. V. Halushka, "Testosterone increases human platelet thromboxane A2 receptor density and aggregation responses," Circulation, vol. 91, no. 11, pp. 2742-2747, 1995.

[26] K. Matsuda, A. Ruff, T. A. Morinelli, R. S. Mathur, and P. V. Halushka, "Testosterone increases thromboxane A2 receptor density and responsiveness in rat aortas and platelets," American Journal of Physiology, vol. 267, no. 3, pp. H887-H893, 1994. 


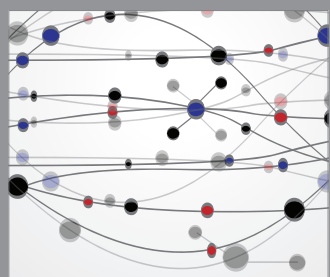

The Scientific World Journal
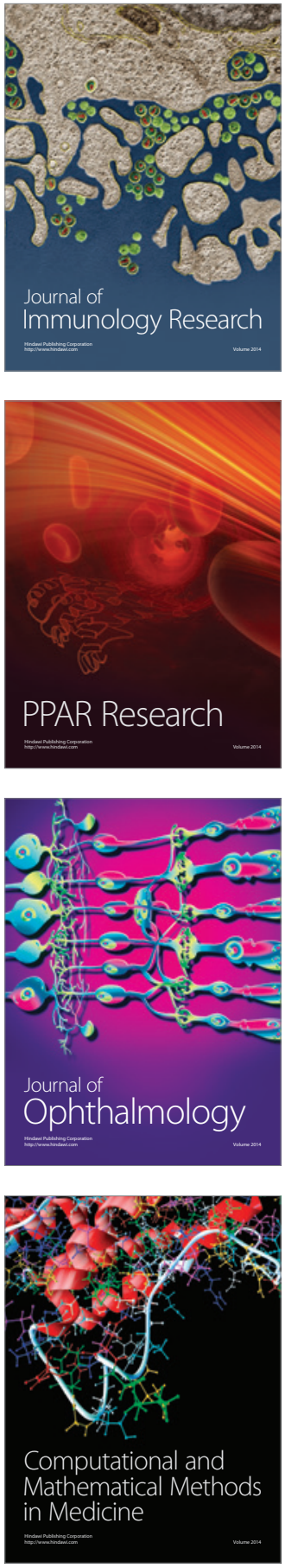

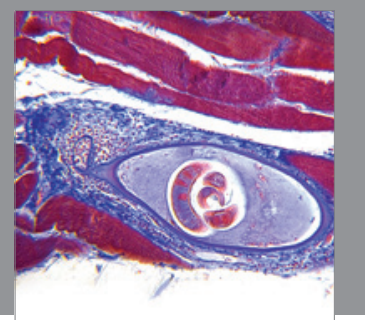

Gastroenterology

Research and Practice
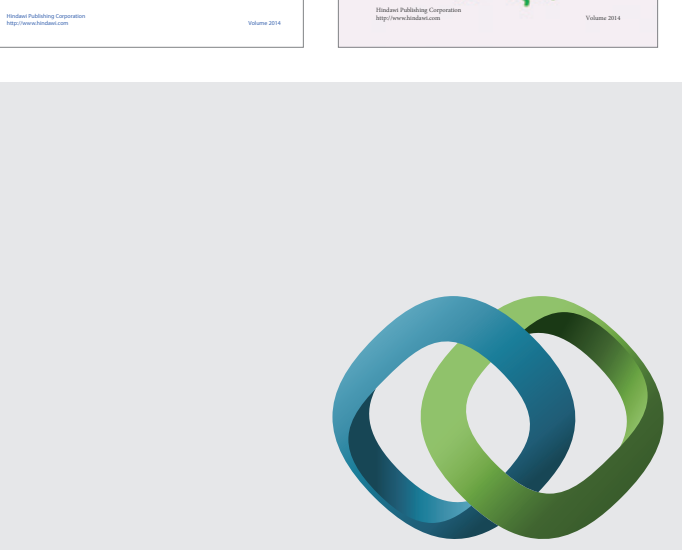

\section{Hindawi}

Submit your manuscripts at

http://www.hindawi.com
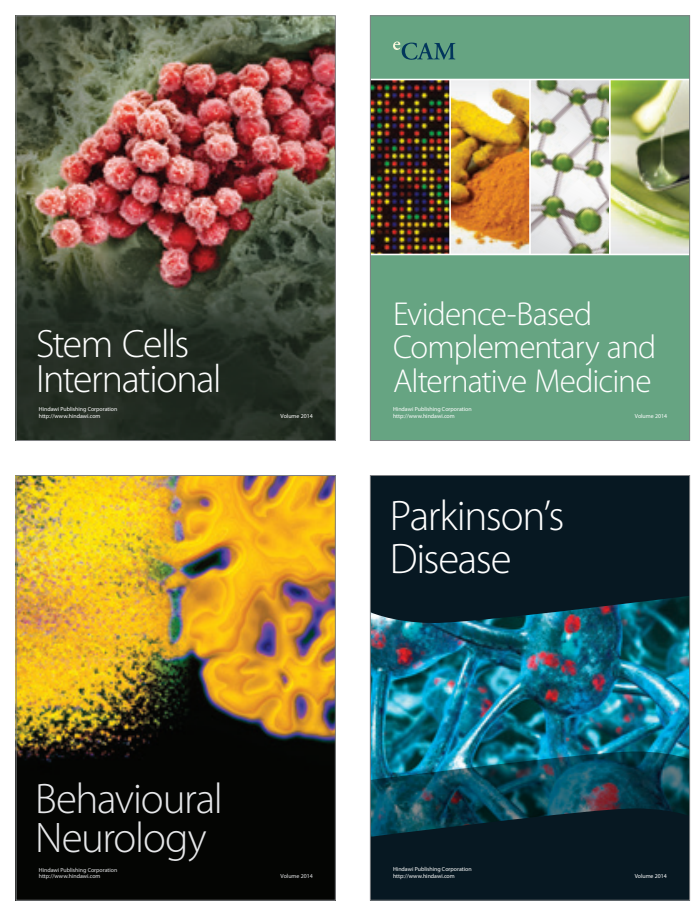

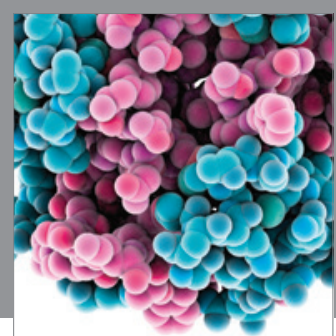

Journal of
Diabetes Research

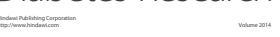

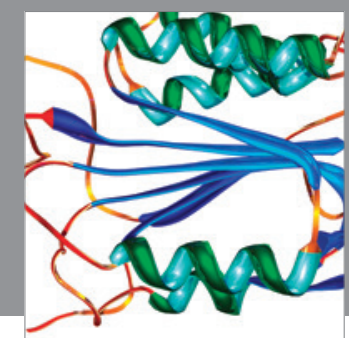

Disease Markers
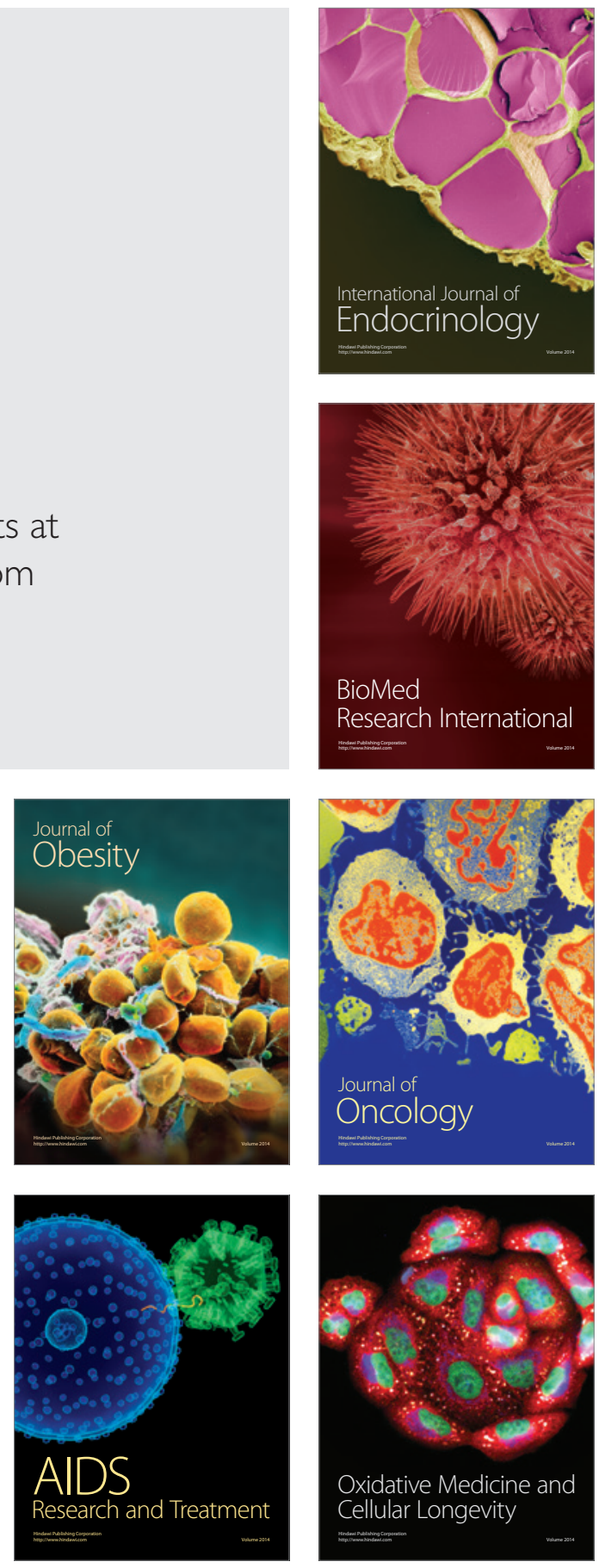